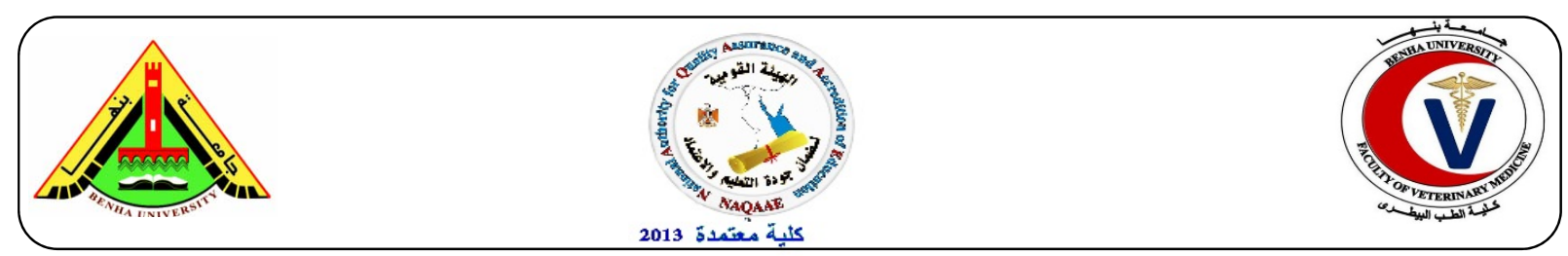

\title{
Pasteurella multocida in camels: incidence, capsular and virulence genes characterization
}

\author{
${ }^{1}$ Ashraf A. Abd El Tawab, ${ }^{1}$ Fatma I. El -Hofy, ${ }^{2}$ Attia Al-Jeddawy and ${ }^{2}$ Ebtehal Abo-Hamdah \\ ${ }^{1}$ Bacteriology, Immunology and Mycology Department, Faculty of Veterinary Medicine Benha University. ${ }^{2}$ Animal \\ Health Research Institute, Dokki - Giza.
}

\begin{abstract}
A B S T R A C T
Pasteurella multocida is the main cause of hemorrhagic septicemia in camels. This study deals with the isolation and molecular examination of hemorrhagic septicemia in camels from May 2014 to March 2016 from 30 camel nasal swabs in Marsa Matruh and 120 camel lungs (70 slaughtered in Basateen abattoir in Giza Governorate and 50 slaughtered in AlShohada abattoir at Al-Menofia Governorate). All collected samples were subjected to clinical, postmortem examination as well as for bacteriological and molecular examination. Totally P. multocida was isolated from the examined samples with percentage of 5(3.3\%). While the percentage of the isolation rate from 120 camel lungs was 5(4.2\%). In contrast, all 30 nasal swabs were negative. In the pathogenicity test, all P.multocida isolates were highly pathogenic. Pasteurella multocida isolates were identified by PCR and 23 S RNA gene was amplified at 1432bp. Three out of five isolates were identified as P.multocida type B with amplification at $760 \mathrm{bp}$ while other two isolates identified as P.multocida type A and amplified at $1044 \mathrm{bp}$. Also, PCR showed that toxA gene was amplified in all isolates and giving product of $864 \mathrm{bp}$ but ptfA gene was not detected. As conclusion, P.multocida in camels can be diagnosed with different methods such as confirmatory biochemical and molecular assays.
\end{abstract}

Keywords: Pasteurella multocida, Hemorrhagic septicemia, camel, Egypt.

(http://www.bvmj.bu.edu.eg)

(BVMJ-31(2):171 -175, 2016)

\section{INTRODUCTION}

Pasteurella multocida, a member of family Pasteurellaceae, is responsible for hemorrhagic septicemia (HS) or pasteurellosis in camels all over the world (Harper et al., 2014; Mochabo et al., 2005). Pasteurella multocida is considered to be a part of the normal respiratory flora of camels and other animals but it becomes pathogenic and causes the disease when the resistance of the camel body is lowered by harmful environmental influences such as sudden changes in weather, transportation over long distances, deficiencies of dietary nutrition and heavy parasitic infestation as trypanosomiasis (Ewers et al., 2004; Saber, 2006). Morbidity of pasteurellosis is low, but mortality may be high $(80 \%)$. Carrier or sick camels consider as source of infection to other animals specially in young calves. P.multocida causes a septicemia in camels within 10-24 hours, leading to fever, swelling in the throat region, pulmonary edema, fibrinous pneumonia, diarrhea and death usually occurs within 2-3 days (Saber, 2006). Identification of $P$. multocida depends upon the isolation and identification of the organism from suspected materials by cultural, morphological and biochemical characters done (Patel, 2004; Townsend et al., 1998). Also, PCR is used to accurate, rapid detection of toxigenic $P$. Multocida from swabs and tissues (Carol et al., 1996). Multiplex PCR is an alternative to comparative phenotypic tests for the capsular typing of P.multocida, for simultaneous and rapid detection of genes that provides a greater capacity for strain typing (Furian et al., 2014). Therefore, Pasteurellosis is considered an important disease in camels due to its higher economic losses. The present work was planned to isolate and identify Pasteurella multocida from camels in Egypt.

\section{MATERIAL AND METHODS}

\subsection{Samples collection}

A total of 150 camel's samples were collected from 30 camel nasal swabs in Marsa Matruh (25 with respiratory infection and 5 apparently healthy animals) and 120 lung samples (70 camel lungs from Basateen abattoir in Giza Governorate (60 with respiratory infection and 10 apparently healthy animals) and 50 camel lungs from Al- 
Shohada abattoir in Al-Menofia Governorate), had history of respiratory infection. All of these samples were aseptically collected and transferred immediately in icebox to the laboratory.

\subsection{Bacteriological examination}

The samples were inoculated directly into Brain Heart Infusion (BHI) broth and incubated at $37^{\circ} \mathrm{C}$ for 24 hours then streaked onto blood agar, DAS media and MacConkey agar plates. The suspected colonies which showed typical colonial appearance of P.multocida were identified by morphological and biochemical methods.

\subsection{Biochemical examination}

The suspected colonies of P.multocida isolates were subjected to different biochemical tests such as catalase, oxidase, indole production and sugar fermentation test. Also, Analytical Profile Index 20 $\mathrm{NE}$ test (API $20 \mathrm{NE}$, biochemical rapid test, BioMerieux, France) was done.

\subsection{Pathogenicity test}

Pathogenicity of the identified P.multocida isolates was determined by inoculation into BHI broth and incubated at $37^{\circ} \mathrm{C}$, then $(0.2 \mathrm{ml})$ Inoculum of the isolates was injected intraperitonially into the Swiss Albino mice then identified and recorded the time of death of each mouse during the next 24 hours.

\subsection{Multiplex PCR assay}

PCR amplify-cation of 23S ribosomal DNA of P.multocida isolates was carried out using the following primers (table1). DNA was extracted as described by Sambrook et al. (1989) using QIAamp DNA mini kit instructions with minor modification. Only one $\mathrm{ml}$ of cultured colonies in BHI centrifuged then discarded the supernatant and washed the pellets and centrifuged again. After extraction of DNA of each bacterial isolates PCR master mix was prepared according to Emerald Amp GT PCR master mix (Takara) Code No. RR310A kit mixing deoxy-nucleoside. Amplified PCR products were run on $1.2 \%$ agarose gel by Agar gel electrophoresis and visualized by gel documentation system (Kodak) after staining by ethidium bromide.

\section{RESULTS}

\subsection{Clinical signs and P.M. Lesions on investigated camels}

A total of 150 samples from camels were collected (30 nasal swabs and 120 lungs). Clinically diseased camels showed signs of mucopurulent nasal discharge, Pyrexia (fever might reach $40^{\circ} \mathrm{C}$ ) in case of septicemia, salivation, lacrimation, anorexia, occasionally diarrhea which sometimes contain blood. Also, diseased camel died within 9 days. P.M. lesions were purulent bronchopneumonia, hydrothorax, emphysema, fibrinous pericarditis, red and gray hepatization, inflammation of thoracic lymph nodes with hemorrhage, adhesion of the lung to the thorax and general congestion in internal organs especially pneumonic lung.

\subsection{Bacteriological and Biochemical identification of P.multocida isolates}

On blood agar and DAS medium ( $1 \%$ crystal violet) after incubated anaerobically at $37^{\circ} \mathrm{C}$ for $24 \mathrm{hrs}$, all the isolates of P.multocida produced smooth or mucoid, non-hemolytic, round, grayish colonies and accompanied by a characteristic "mousy" odor due to metabolic products. While, the isolates of P.multocida failed to grow on MacConkey's agar. P.multocida showed as gram negative, non-motile coccobacillary rods and a distinct bipolar staining reaction with Leishman's stain. Also suspected positive cultural colonies was subjected to biochemical and confirmatory API 20 $\mathrm{NE}$ tests and showed identical biochemical reaction to P.multocida (Table 2).

\subsection{Incidence of P.multocida in camels}

An incidence of isolation of P.multocida from total 150 samples was $5(3.3 \%)$. While the percentage of isolation of P.multocida from 120 lungs was 5(4.2\%) and (0\%) from 30 nasal swabs (table 3).

\subsection{Pathogenicity test}

All five P.multocida isolates (Biochemical identified) after inoculation in mice were highly pathogenic where all inoculated mice were dead within $24 \mathrm{hrs}$ with P.M. finding of septicemia and P.multocida was reisolated from heart blood and showing specific bipolarity of P.multocida organism by Leishman's stain.

\subsection{Multiplex PCR assay}

In this study five isolates found to be positive for P.multocida with the same percentage obtained by API 20NE and giving amplified segment product of $1432 \mathrm{bp}$. Also, the results of capsular typing of P.multocida and detection of some virulent genes (toxA, pdfA) of P.multocida by PCR were 3 isolates identified as P.multocida type B and amplified at $760 \mathrm{bp}$ while (2) isolates identified as P.multocida type A and amplified at 1044bp. 
Table I: Primers used for the detection of virulence-associated genes in isolates.

\begin{tabular}{|c|c|c|c|}
\hline Target gene & Primers sequences & $\begin{array}{l}\text { Amplified } \\
\text { segment (bp) }\end{array}$ & Reference \\
\hline 23S Rrna & $\begin{array}{l}\text { GGC TGG GAA GCC AAA TCA AAG } \\
\text { CGA GGG ACT ACA ATT ACT GTA A }\end{array}$ & 1432 & $\begin{array}{l}\text { (Miflin and Blackall, } \\
2001) \& \text { (OIE } \\
\text { Terrestrial, 2012) }\end{array}$ \\
\hline Serogroup A & $\begin{array}{l}\text { TGC-CAA-AAT-CGC-AGT-GAG } \\
\text { TTG-CCA-TCA-TTG-TCA-GTG }\end{array}$ & 1044 & \\
\hline Serogroup B & $\begin{array}{l}\text { CAT-TTA-TCC-AAG-CTC-CAC-C } \\
\text { GCC-CGA-GAG-TTT-CAA-TCC }\end{array}$ & 760 & \\
\hline Serogroup E & $\begin{array}{l}\text { TCC-GCA-GAA-AAT-TAT-TGA-CTC } \\
\text { GCT-TGC-TGC-TTG-ATT-TTG-TC }\end{array}$ & 511 & \\
\hline ToxA & $\begin{array}{l}\text { CTTAGATGAGCGACAAGG } \\
\text { GAATGCCACACCTCTATAG }\end{array}$ & 864 & (Tang et al., 2009) \\
\hline PtfA & $\begin{array}{l}\text { TGTGGAATTCAGCATTTTAGTGTGTC } \\
\text { TCATGAATTCTTATGCGCAAAATCCT } \\
\text { GCTGG }\end{array}$ & 488 & \\
\hline
\end{tabular}

Table (2) Results of biochemical identification of the isolated Pasteurella multocida using standard laboratory testes:

\begin{tabular}{cl}
\hline Result & Biochemical tests \\
\hline$+\mathrm{ve}$ & Oxidase \\
$+\mathrm{ve}$ & Catalase \\
$+\mathrm{ve}$ & Indole production \\
$-\mathrm{ve}$ & Growth on MacConkey's'agar \\
$-\mathrm{ve}$ & Urease test \\
$+\mathrm{ve}$ & TSI \\
$-\mathrm{ve}$ & M.R .and V.P. tests \\
$-\mathrm{ve}$ & Hemolysis on blood agar \\
$-\mathrm{ve}$ & Citrate utilization \\
$+\mathrm{ve}$ & Nitrate reduction \\
$+\mathrm{ve}$ & Glucose \\
$+\mathrm{ve}$ & Mannitol \\
$+\mathrm{ve}$ & Sucrose \\
$+\mathrm{ve}$ & Mannose \\
$-\mathrm{ve}$ & Maltose \\
$-\mathrm{ve}$ & Arabinose \\
$-\mathrm{ve}$ & Lactose \\
$-\mathrm{ve}$ & Dulcitol \\
$-\mathrm{ve}$ & Salicin \\
$-\mathrm{ve}$ & Inositol \\
$-\mathrm{ve}$ & Trehalose \\
\hline
\end{tabular}

Table (3) The percentage of Pasteurella multocida isolated from Lungs and nasal swabs of one humbled camels from different geographical areas examined by biochemical examination and API 20 NE technique.

\begin{tabular}{llccccc}
\hline $\begin{array}{l}\text { Type } \\
\text { Of samples }\end{array}$ & Area & No. of examined samples & \multicolumn{3}{c}{ Results } \\
& & \multicolumn{2}{c}{$\begin{array}{l}\text { No of } \\
\text { +ve samples }\end{array}$} & $\begin{array}{l}\text { No. of } \\
\text {-ve samples }\end{array}$ & $\%$ \\
\hline Nasal swabs & Mursa Matruh & 30 & 0 & $0 \%$ & 100 & $100 \%$ \\
Lungs & Bassatine abattoir & 70 & 1 & & 115 & $95.8 \%$ \\
& Al-Shohada abattoir & 50 & 4 & & & \\
& Total & 120 & 5 & $4.2 \%$ & & $96.6 \%$ \\
\hline
\end{tabular}


Table (4): Results of molecular investigation of P.multocida isolates by multiplex PCR.

\begin{tabular}{clcllll}
\hline Sample & Kmt & Serotype & Serotype & Serotype & toxA & ptfA \\
& Result & A & B & E & & \\
\hline 1 & Not done & - & + & - & + & - \\
2 & Not done & - & + & - & + & - \\
& & - & & & & \\
3 & Not done & - & + & - & + & - \\
4 & Not done & + & - & - & + & - \\
5 & Not done & + & - & - & + & - \\
\hline
\end{tabular}

Also toxA gene was amplified in all isolates and giving product of $864 \mathrm{bp}$ but $p t f A$ gene was not detected in any P.multocida isolates (table4).

\section{DISCUSSION}

Pasteurella multocida is the main cause of hemorrhagic septicemia in camels. In the present study, five isolates from total 150 samples (30 nasal swabs and 120 lungs) were found to be positive for Pasteurella multocida with an incidence of $(3.3 \%)$. This results was nearly in coordinating with that reported by Abo-Elnaga and Wafaa (2012) who examined 175 lungs from camels slaughtered at Matrouh main abattoirs. They found that, the incidence rate of $P$. multocida was $(2.9 \%$. Also, Wareth et al. (2014) who examined a total of 500 lung tissues from apparently healthy camels which imported from Sudan and Slaughtered at El-Warrak slaughter house and they isolated Pasteurella spp. at an incidence of $2.85 \%$. While such results disagree with Kibruyesfa (2015) who isolated Pasteurella spp. from 207 camel lungs from slaughtered camels at Addis Ababa Akaki Abattoirin an incidence of $5.7 \%$.

In this study, the bacteriological and microscopical examination of P.multocida isolates showed short bacillary forms giving a distinct bipolar staining reaction with Leishman's stain. The suspected growing colonies were studied by morphological, confirmatory biochemical and API 20 NE examination and revealed five isolates identified as P.multocida. This result agreed with those of Seleim et al. (2003) and Jabeen et al. (2013).

The recorded results of pathogenicity of five isolated pasteurella multocida isolates in mice proved that all isolates were highly virulent and pathogenic to mice with a mean death time 24 hours with P.M.finding of septicemia. These results agreed with those of Townsend et al. (2000) and OIE Terrestrial (2008). Multiplex PCR was used for capsular typing and detection of some virulence genes (toxA and ptfA) of isolated $P$. multocida. The results of molecular examination were five $P$. multocida isolates in same percentage of which obtained by confirmatory API 20NE were identified and 23S RNA gene was amplified at $1432 \mathrm{bp}$. Also 3 isolates identified as P.multocida type B and amplified at $760 \mathrm{bp}$. While 2 isolates identified as P.multocida type A and amplified at 1044bp. Also toxA gene was amplified in all isolates and giving product of $864 \mathrm{bp}$ but $p t f A$ gene was not detected in any P.multocida isolates. These results agreed with Tahamtan et al. (2016) who proved that capsular PCR assay identified P.multocida serotype A and B in camels by the specific primers for capsular types A and B amplifying 1044 and 760 bp respectively. So P.multocida type B was the main cause of hemorrhagic septicemia in camels. Also Sahragard et al. (2011) developed a multiplex PCR in the P.multocida isolates which more rapid and specific than biochemical analysis and mice bioassay and toxA gene was found in all P.multocida isolates.

\section{CONCLUSION}

Camel Pasteurellosis is considered to be important epidemiological and diagnostic diseases in camels due to economic losses amongst the camels and need more studies to management and control the disease in Egypt .

\section{REFERENCES}

Abo-Elnaga, T.R., Wafaa, A.O., 2012. Detection of Pathogens of Condemned Lungs of One Humped Camels (Camelusdromedarius)Slaughtered in Matrouh Abattoirs. Egypt.Global Veterinaria 9, 290-296.

Carol, A.L., Susan, M.S., Daled, P.R., Lee, A.V., 1996. Direct PCR Analysis for Toxigenic Pasteurella multocida. Journal of clinical microbiology 34, 3035-3039.

Ewers, C., Lubke-Becker, A., Wieler, L.H., 2004. Pasteurella: insights into the virulence determinants of a heterogenous bacterial 
type. Serl. Munch. Tierarztl.Wochenschr 117, 367-386.

Furian, T.Q., Borges, K.A., Pilatti, R.M., Almeida, C., do Nascimento, V.P., Salle, C.T.P., Moraes, H.L.D., 2014. Identification of The Capsule Type of Pasteurella Multocida Isolates from Cases of Fowl Cholera by Multiplex PCR and Comparison with Phenotypic Methods. Braz J Poultry Sci 16, 31-36.

Harper, M., St. Michael, F., John, M., Steen, J.M., van Dorsten, L., Parnas, H., Vinogradov, E., Adler, B., Boyc, J., 2014. Structural analysis of lipopolysaccharide produced by Heddlestonserovars 10, 11, 12 and 15 and the identification of a new Pasteurellamultocida lipopolysaccharide outer core biosynthesis locus, L6. Glycobiology 24, 649-659.

Jabeen, A., Mahrukh, K., Shahzad, M., Qaiser, J., Mubashir, H., 2013. Antibiotic Susceptibility and Molecular Analysis of Bacterial Pathogen PasteurellaMultocida Isolated from Cattle. Journal of Applied Pharmaceutical Science 3, 106-110.

Kibruyesfa, B. 2015. Characterization, bacterial isolation and viral detection from respiratory tract of dromedary camels slaughtered at Addis Ababa Akaki Municipal Abattoir, Ethiopia., College of Veterinary Medicine and Agriculture of Addis Ababa, Ethiopia.

Miflin, J.K., Blackall, P.J., 2001. Development of a 23S rRNA-based PCR assay for the identification of Pasteurella multocida. Lett Appl Microbiol 33, 216-221.

Mochabo, K.O., Kitala, P.M., Gathura, P.B., Ogara, W.O., Catley, A., Eregae, E.M., Kaitho, T.D., 2005. Community perceptions of important camel diseases in Lapur Division of Turkana District, Kenya. Trop Anim Health Pro 37, 187-204.

OIE Terrestrial, M., 2008. Haemorrhagic Septicaemia. J. clin. microbial. 2, 4-12

OIE Terrestrial, M., 2012. Heamorrahagic septicemia. chapter 2, 4-1 2

Patel, H.K. 2004. Biochemical characterization, antimicrobial sensitivity, PCR-based detewction and mouse pathogenicity of pasteurella multocida in field isolates

AgriculturalUniversity.

Saber, W., 2006. Pasteurellosis.Veterpedai Topics $\&$ NewsCategory. Overview of the Disease.

Sahragard, I., Tahamtan, Y., Valadan, M., Masoumeh, H., Moazeni, F., Zahra, S., 2011. Development of rapid PCR method for simultaneous identification of species, specific capsular type and toxigenicity of Pasteurella sp. Isolates.Comp Clin. Pathol.

Sambrook, J., Fritscgh, E.F., Mentiates, 1989. Molecular coloning.A laboratory manual. Cold spring Harbor Laboratotry press, New York.

Seleim, R.S., Nada, H.S., Sahar, R., Mohamed, S.R., Gobran, R.A.a., TOS, A.R., 2003. Eliza and other testes in diagnosis of pasteurella multocida infection in camels. Conference on international Agriculture Rsearch for development.

Tahamtan, Y., Amrabadi, O., Shahryari, R., 2016. Identification of Pasteurella multocida and molecular diagnosis of haemorrhagic septicaemia in Iranian camels. Rev Med VetToulouse 167, 126-132.

Tang, X., Zhao, Z., Hu, J., Wu, B., Cai, X., He, Q., Chen, H., 2009. Isolation, antimicrobial resistance, and virulence genes of Pasteurella multocida strains from swine in China. J Clin Microbiol 47, 951-958.

Townsend, K.M., Frost, A.J., Lee, C.W., Papadimitriou, J.M., Dawkins, H.J., 1998. Development of PCR assays for species- and type-specific identification of Pasteurella multocida isolates. J Clin Microbiol 36, 1096-1100.

Townsend, K.M., Hanh, B., Wilkie, P., Wijewardana, T.G., Trung, F., 2000. PCR detection of analysis of Pasteurellamultocida from the tonsils of slaughtered pigs in vietnam. Vet. Microbiol. 7, 69-78.

Wareth, G., Murugaiyan, J., Khater, D.F., Moustafa, S.A., 2014. Subclinical pulmonary pathogenic infection in camels slaughtered in Cairo, Egypt. J Infect Dev Ctries 8, 909-913. 